\title{
Evaluation of long-term breast shape in inferior versus superomedial pedicle reduction mammoplasty: a comparative study
}

\author{
Gianluca Sapino ${ }^{1,2}$, Daniel Haselbach ${ }^{1}$, William Watfa ${ }^{1,3}$, Julien Baudoin ${ }^{1}$, Jérôme Martineau ${ }^{1}$, \\ David Guillier $^{1,4}$, Pietro Giovanni di Summa ${ }^{1}$
}

${ }^{1}$ Department of Plastic, Reconstructive, Aesthetic and Hand Surgery, University Hospital of Lausanne (CHUV), Lausanne, Switzerland; ${ }^{2}$ Department of Plastic and Reconstructive Surgery, University Hospital of Modena, Modena, Italy; ${ }^{3}$ Department of Plastic and Reconstructive Surgery, Saint George Hospital University Medical Center, Beirut, Lebanon; ${ }^{4}$ Department of Plastic Reconstructive and Hand Surgery, Department of Oral and Maxillofacial Surgery - University Hospital, Boulevard de Lattre de Tassigny F-21000, Dijon, France

Contributions: (I) Conception and design: G Sapino, PG di Summa; (II) Administrative support: All authors; (III) Provision of study materials or patients: D Haselbach, W Watfa, J Baudoin, PG di Summa; (IV) Collection and assembly of data: G Sapino, J Martineau, PG di Summa; (V) Data analysis and interpretation: G Sapino, J Martineau, PG di Summa; (VI) Manuscript writing: All authors; (VII) Final approval of manuscript: All authors.

Correspondence to: PD-MER Dr. Pietro Giovanni di Summa, MD, PhD. Consultant, Department of Plastic, Reconstructive and Hand Surgery, Centre Hospitalier Universitaire Vaudois (CHUV), Lausanne, Switzerland, Rue du Bugnon 461011 Lausanne, Switzerland. Email: Pietro.di-Summa@chuv.ch.

Backgroundk Among breast reduction mammoplasty, the inferior pedicle-based (IFP) technique is considered the most performed by plastic surgeons. A growing interest for the supero-medial based pedicle (SMP) mammoplasty technique has been documented in literature and clinical practice. However, no real evidence exists on the superiority of one technique over another.

Methods: This study represents a retrospective multimodal analysis, using a prospectively maintained database, comparing wise pattern breast reduction techniques (IFP vs. SMP) over a 24-month follow-up. From January 2015 to July 2017, all patients undergoing wise pattern bilateral reduction mammoplasty, using either an IFP or a SMP technique, were included in the study and divided in two groups. Preoperative breast measurements included sternal notch-to-nipple distance ( $\mathrm{SN}-\mathrm{N}$ ), infra-mammary fold to inferior border of Nipple Areolar Complex (NAC) distance length and ptosis. The same measurements were recorded at 2 weeks, 6 months and 24 months post-op. Complications were recorded and aesthetic outcomes were evaluated.

Results: A total of 58 patients were included in the study, among which 36 (62\%) were treated with a SMP technique and 22 (38\%) with an IFP technique. At the 24-month follow-up timepoint, the SN-N distance was significantly shorter $\left({ }^{*} \mathrm{P}<0.05\right)$ in the SMP group, with a significantly smaller elongation of the lower pole arc $(29.5 \%$ increase in length in the SMP group and $40.9 \%$ in the IFP group). Aesthetic result gave significantly higher mean VAS score for SMP patients compared to IFP patients.

Conclusions: The SMP technique provides stable and satisfactory results in term of breast shape, overcoming some of the major concerns related to the use of an IFP technique (lower pole elongation and ptosis recurrence), maintaining a superimposable complication rate.

Keywords: Breast reconstruction; supero-medial pedicle; inferior pedicle; breast shape

Submitted Apr 04, 2020. Accepted for publication Jan 15, 2021.

doi: $10.21037 / g s-20-440$

View this article at: http://dx.doi.org/10.21037/gs-20-440 


\section{Introduction}

Breast reduction mammoplasty is among the ten most commonly performed cosmetic procedures worldwide (1). In fact, heavy and hypertrophic breasts result in psychological and physical discomfort, and are associated with a wide array of symptoms ranging from back pain and intertriginous rashes of the inframammary fold, to depression and loss of self-confidence (2). Since surgical treatment remains the most efficient way to relief these symptoms, a number of surgical techniques have been described throughout the years by proposing different pedicles and skin excision patterns. The key common objective of such procedures is to reconstitute a natural breast shape by the removal of both excessive skin and adipo-glandular tissue while maintaining the nipple-areola complex (NAC) well vascularized. These techniques differ from one another mainly by the way the NAC is transposed in its new position.

Despite the fact that in the literature no technique has proven to be the best, the inferior pedicle-based (IFP) technique remains by far the most performed by American plastic surgeons, as it is considered to provide the best vascularization to the NAC, allowing safe removal of large amount of redundant tissue $(3,4)$.

During the last few years, a growing interest for the supero-medial based pedicle (SMP) mammoplasty technique has been documented in literature and clinical practice. According to recent publications, in expert surgeon's hand, this technique may lead to a better cosmetic outcome (with less "bottoming out" and more medial breast fullness) maintained over time, shorter operative time, without an increased risk of NAC necrosis resulting in higher patient satisfaction (5).

However, no real evidence exists on the superiority of one or another technique, as no studies could quantitatively and statistically compare breast measurements and shapes as a result of different techniques in the long term.

This study performs a retrospective multimodal analysis based on a prospectively maintained database, comparing wise pattern breast reduction techniques (inferior $v s$. supero-medial pedicle) from a single center over a 2 years follow-up. Quantitative data on breast measures and shape evolution was detected over time. Aesthetic assessment and analysis of outcomes and complications are reported and discussed.

We present the following article in accordance with the STROBE reporting checklist (available at http://dx.doi. org/10.21037/gs-20-440).

\section{Methods}

A retrospective review was performed on a prospectively maintained database from January 2015 to July 2017. All patients scheduled for wise pattern bilateral reduction mammoplasty for macromastia were included in the study and divided in two groups depending on which surgical technique was used to perform the breast reduction: either inferior pedicle (IFP) or supero-medial pedicle (SMP). Patients were consecutive and the division in two groups reflects the predominance of one technique (IFP) over the other (SMP) during the first examined period, progressively shifting the indication towards SMP reduction according to leading surgeon preference. Patients treated with techniques which were neither IFP nor SMP (e.g., Thorek, Mckissock, superior pedicle, supero-lateral pedicle) nor inverted " $T$ " skin excision patterns (e.g., vertical, peri-areolar, J shaped) were not included in the study. Also excluded were all female patients who underwent reduction mammoplasty to treat congenital breast asymmetry or oncoplastic procedure for oncologic surgery and all male patients.

Patients age, body mass index (BMI) and comorbidities were collected from medical and anesthesiologic charts. Operative notes were screened for technique details and the amount of breast volume removed. Hospital letters and outpatient reports were used to evaluate the hospital stay, the number of days the drains were kept, as well as early and late complications.

The study was conducted accordingly to the guiding principles following the Declaration of Helsinki (as revised in 2013). Informed consent was obtained from all patients, including approval for photographic \video documentation. The 'Commission cantonale d'éthique de la recherche sur l'être humain CER-VD' approved the study, project ID 02512 .

\section{Preoperative markings and measures}

With the patient in a sitting position, pre-operative breast measurements were performed by a plastic surgery fellow with a simple metric tape. They included sternal notch-to-nipple distance ( $\mathrm{SN}-\mathrm{N})$, infra-mammary fold to inferior border of NAC distance (segment III), ptosis and pseudoptosis (quantified as $\mathrm{cm}$ of breast drooping under the IMF, according to Regnault) (6) and the NAC average diameters. The same measurements were recorded 
during the follow-up period in the outpatient clinic by a plastic surgery resident blinded to the study, particularly at 2 weeks, 6 months and 24 months post-op. Only patient with complete follow-up were included in the study.

Post-operative complications were recorded and divided into major (those requiring a return to the operating room) and minor.

Asymmetry of breast was recorded preoperatively and postoperatively and aesthetic result was evaluated using clinical photos taken during the last follow-up, by both the patient and the examining surgeon blinded to the study using the Visual Analog Scale (VAS, 0-10). Clinical photography consisted of patient standing comfortably upright with arms at sides, and 5 views were performed (frontal, obliques, and lateral). Framing was standardized with the position of clavicles at the top of the image and camera at patient distance of $1 \mathrm{~m}$.

\section{Surgical techniques}

All procedures were performed or directly supervised by the same senior surgeons (PDS and DG). Preoperative markings were performed according to standard techniques. The breast meridian (midclavicular line), sternal midline and the inframammary fold (IMF) were marked with the patient in standing position. The Pitanguy point was used for the new NAC position on the breast meridian (matching on the mid arm position), just below the projection of the IMF using the index finger, at a distance from the sternal notch ranging from 18 to $22 \mathrm{~cm} \mathrm{(7).} \mathrm{A} \mathrm{keyhole} \mathrm{wise} \mathrm{pattern}$ was used in all patients, maintaining a vertical scar length comprise between 6 and $7 \mathrm{~cm}$ in both groups. The superomedial pedicle (SMP) was marked on the medial limb of the vertical scar, while the inferior pedicle (IFP) of at least $8 \mathrm{~cm}$ width was marked across the midclavicular line. In both cases, the pedicle was then de-epithelized and the breast tissue resection was performed en bloc. Moderate undermining of the pedicle was performed to maximize perforators inflow coming from the internal mammary artery and the intercostal arteries. The NAC was rotated around 90 degrees, for SMP, or advanced, for IFP, to its new position avoiding tension. The same procedure was performed contralaterally. The two breasts were checked for symmetry with temporary staple closure and control in sitting position. Subcutaneous Blake drains were placed bilaterally. Skin closure was performed using 2-0 Vicryl for deep sutures and 3-0/4-0 Monocryl for subcutaneous (Ethicon, J\&J, USA) and dermis. Patient was advised to wear a surgical support bra for 6 weeks post-operatively. The patient remained hospitalized until drains removal, (volume less then $40 \mathrm{~mL}$ in 24 hours).

\section{Statistical analysis}

Patients groups were compared using independent twosided $t$-tests for means, Mann-Whitney $U$ tests for medians and two-sided Chi-square or Fisher's exact test as appropriate in order to analyze categorical variables. We verified the assumption of normality using the ShapiroWilk test. We used univariate linear regression to compare both group measurements over time. Statistical significance was set at a $\mathrm{P}$ value $<0.05$. Statistical analysis was performed using GraphPad Prism (version 8.0, GraphPad software, La Jolla, CA).

\section{Results}

During this specific period, 64 breast reduction procedures were performed and retrospectively analyzed. After application of inclusion and exclusion criteria, 58 consecutive women (116 breasts) were retained in the study, among whom $36(62 \%)$ were treated with a SMP technique and $22(38 \%)$ with an IFP breast reduction technique. Two patients (one in each group) did not complete the minimum follow-up and were therefore excluded.

The 2 groups were comparable in terms of both baseline characteristics and preoperative breast shape measurements. The average age at the time of the procedure was 34 years and (range, 16-67 years) in the SMP group and 38 years and (range, 17-66 years) in the IFP group. The patient's mean BMI was $29 \mathrm{~kg} / \mathrm{m}^{2}$ (range, $21.9-33.9 \mathrm{~kg} / \mathrm{m}^{2}$ ) in the SMP breast reduction group and $28.4 \mathrm{~kg} / \mathrm{m}^{2}$ (range, $21.3-$ $39.4 \mathrm{~kg} / \mathrm{m}^{2}$ ) in the IFP group. In the SMP group, the resection weight ranged from 270 to $1,800 \mathrm{~g}$ with a mean resection weight of $699 \mathrm{~g}$ per breast. In the IFP group, the resection weight ranged from 98 to $1,735 \mathrm{~g}$ with a mean resection weight of $602.1 \mathrm{~g}$ per breast (Table 1).

\section{Preoperative assessment measurements}

Breast measurements were analyzed on a per-breast basis, given that only bilateral breast reduction surgeries were performed. The average preoperative $\mathrm{SN}-\mathrm{N}$ distance was $31.4 \mathrm{~cm}$ in the SMP group and $31.2 \mathrm{~cm}$ in the IFP group. The average preoperative distance between the IMF and inferior border of the NAC was $12.9 \mathrm{~cm}$ in the SMP 
Table 1 Patients characteristics

\begin{tabular}{|c|c|c|c|}
\hline & $\operatorname{SMP}(n=36)$ & IFP $(n=22)$ & $P$ value \\
\hline BMI $\left(\mathrm{kg} / \mathrm{m}^{2}\right)$, mean $(\mathrm{SD})$ & $29(4.2)$ & $28.4(4.8)$ & 0.6355 \\
\hline Smoker, n (\%) & $7(19.5 \%)$ & $4(18.2 \%)$ & 0.9053 \\
\hline Reduction weight (g) per breast, mean (range) & $698.9(270-1,800)$ & $602.1(98-1,735)$ & 0.1390 \\
\hline Left-side, mean (SD) & $700.6(363.1)$ & $627.1(412.2)$ & 0.4053 \\
\hline
\end{tabular}

Table 2 Patients preoperative measurements

\begin{tabular}{|c|c|c|c|}
\hline & SMP $(n=72)$ & IFP $(n=44)$ & $P$ value \\
\hline Infra-mammary fold to inferior border of NAC, mean (SD) & $12.9(3.2)$ & $12.5(3.9)$ & 0.1278 \\
\hline NAC diameter, mean (SD) & $8.6(2.7)$ & $10.3(6.3)$ & 0.2006 \\
\hline Ptosis, mean (SD) & $8.5(2.8)$ & $9.5(5.4)$ & 0.8482 \\
\hline
\end{tabular}

group and $12.5 \mathrm{~cm}$ in the IFP group. The length of breast segment dropping under the IMF, which was considered a sign of ptosis/pseudoptosis, was $8.5 \mathrm{~cm}$ in the SMP group and $9.5 \mathrm{~cm}$ in the IFP group. All differences between the two groups concerning the above-mentioned measurements were not statistically significant (Table 2).

\section{Postoperative assessment measurements}

Please refer to Table 3 for post-operative assessment measurements. The average postoperative $\mathrm{SN}-\mathrm{N}$ distances in the SMP group vs. the IFP groups were 20.9 vs. $20.9 \mathrm{~cm}$, 21.8 vs. $22.3 \mathrm{~cm}$ and 22.2 vs. $22.7 \mathrm{~cm}$ at the 2-week, 6-month and 24-month follow-up, respectively. The SN-N distance was significantly shorter in the SMP group at both the 6-month and the 24-month follow-up $\left({ }^{*} \mathrm{P}<0.05\right)$ amounting to a mean elongation of the $\mathrm{SN}-\mathrm{N}$ distance of $1.8 \mathrm{~cm}(9.1 \%)$ in the IFP group and $1.3 \mathrm{~cm}(6.5 \%)$ in the SMP group during 24-month follow-up. However, the linear regression slopes of the repeated measurements showed a positive trend without statistical significance $(\mathrm{P}=0.3120)$ (Figure 1).

The mean lower pole length (IMF to inferior border of NAC) of the SMP group and the IFP group were 6.8 vs. $7.0 \mathrm{~cm}, 8.4$ vs. $8.5 \mathrm{~cm}$ and $8.8 v s .9 .7 \mathrm{~cm}$ at the 2 -week, 6-month and 24-month follow-up, respectively. The mean increase in the IMF to inferior border of NAC distance between the 2-week follow-up and the 24-month follow-up was $2.0 \pm 1.7 \mathrm{~cm}$ (average $\pm \mathrm{SD}$ ) in the SMP group and $2.8 \pm 1.3 \mathrm{~cm}$ (average $\pm \mathrm{SD}$ ) in the IFP group $\left({ }^{* *} \mathrm{P}<0.01\right)$, representing a mean elongation (considering the postoperative value as a starting point) of $29.5 \%$ in the SMP group and $40.9 \%$ in the IFP group. Regression slopes were significantly different between both groups $\left({ }^{*} \mathrm{P}<0.05\right)$ (Figure 2).

The average measured pseudoptosis in both groups was $0.2 \mathrm{~cm}$ at the 2-week follow-up. At 6-month follow-up, measured pseudoptosis was significantly $\left({ }^{* * * *} \mathrm{P}<0.0001\right)$ higher in the IFP group, with a mean pseudoptosis of $2.4 \mathrm{~cm}$ compared to a mean pseudoptosis of $1.2 \mathrm{~cm}$ in the SMP group. Similarly, at 24-month follow-up, the measured pseudoptosis in the IFP group was very significantly $\left({ }^{* * *} \mathrm{P}<0.0001\right)$ higher, with an average of 3.9 vs. $2.2 \mathrm{~cm}$ in the IFP group and the SMP group, respectively (Figure 3).

Moreover, concerning skin envelope redraping postoperative inframammary fold scar length was comparable between the groups, suggesting for similar skin envelop redrape. At 2-week follow-up average inframammary fold scar length was $22 \mathrm{~cm}$ in the IFP group and $22.1 \mathrm{~cm}$ in the SMP group. At 6-month follow-up and at 24-month followup, inframammary fold scar length in the IFP group was $21.9 \mathrm{~cm}$ and $22.7 \mathrm{~cm}$ respectively compared to $22.2 \mathrm{~cm}$ and $21.5 \mathrm{~cm}$ in the SMP group. 
Table 3 Patients postoperative measurements

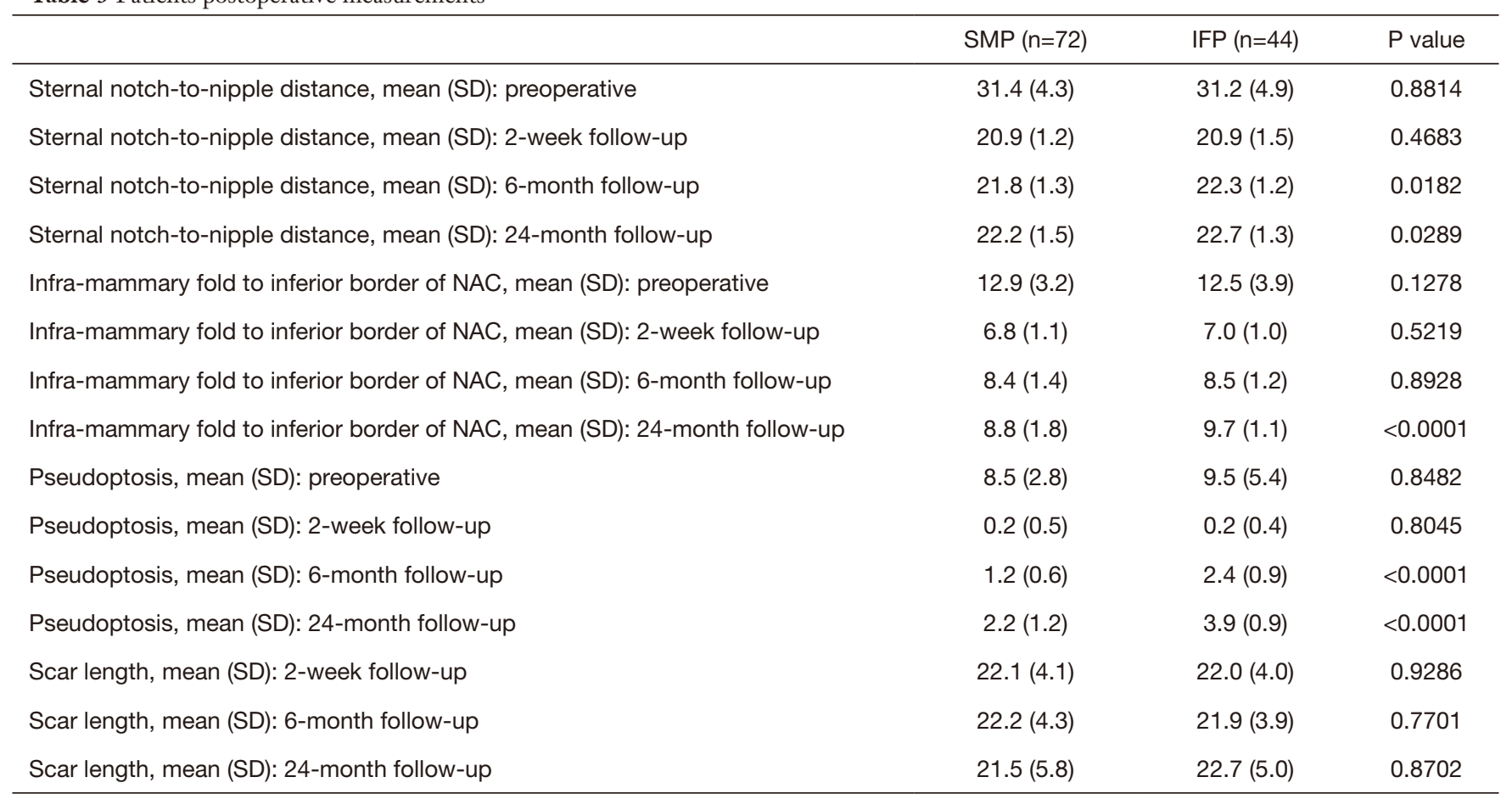

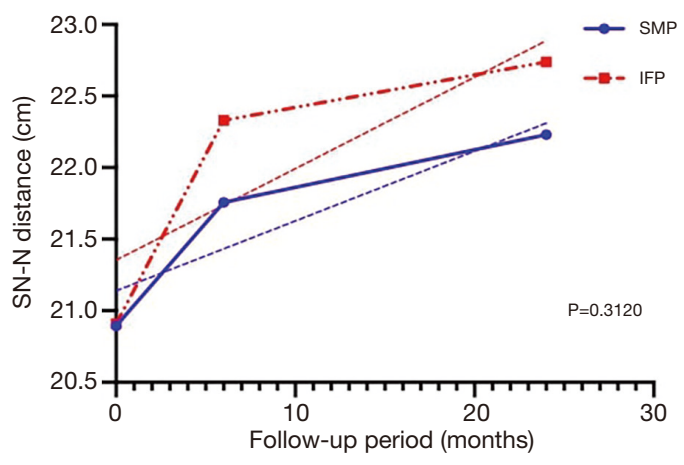

Figure 1 Changes in measured SN-N distance over time.

Both groups showed no difference $(\mathrm{P}=0.9168)$ in rate of enlargement of the NAC diameter over subsequent follow-up visits. However, in the SMP group, we could occasionally notice a stronger tendency to more oval areola pattern developing over time.

\section{Hospital stay and complications}

The average operating time of 156 vs. 171 minutes, showed a trend $(\mathrm{P}=0.1826)$ towards shorter procedures with the SMP when compared with the IFP technique, with no

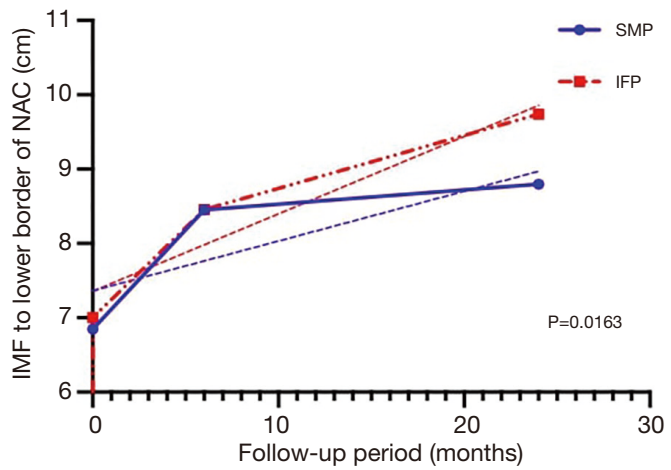

Figure 2 Evolution of the infra-mammary fold to lower border of NAC distance over follow-up visits.

statistically significant difference. Using a median-split separation for weight of resection, the operating time was tendentially $(\mathrm{P}=0.1009)$ longer for larger resections (i.e., $\geq 550 \mathrm{~g}$ removed per breast), regardless of the operating technique. The average hospital stay was similar for both techniques, with a mean stay of 3.3 days in the SMP group and 3.4 days in the IFP group. The mean drainage time was the same in both groups (2.7 days). The mean drainage volume was not significantly different between both groups, with a mean volume of $229 v s .247 \mathrm{~mL}$ in the SMP and 


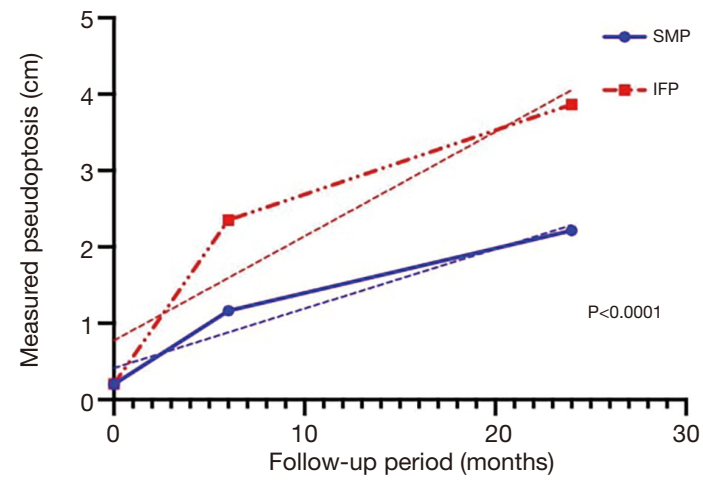

Figure 3 Changes in measured pseudoptosis over time.

Table 4 Patients post-operative complications

\begin{tabular}{lccc}
\hline & SMP $(n=36)$ & IFP $(n=22)$ & P value \\
\hline$\geq 1$ complication & 10 & 9 & 0.3012 \\
Major complication & 0 & 0 & $>0.9999$ \\
Hypertrophic scarring & 7 & 6 & 0.4879 \\
Wound dehiscence & 1 & 1 & $>0.9999$ \\
Asymmetry & 1 & 2 & 0.5508 \\
Seroma & 1 & 1 & $>0.9999$ \\
Infection & 1 & 2 & 0.5508 \\
Liponecrosis & 0 & 1 & 0.3793 \\
Scar revision & 3 & 3 & 0.6638 \\
NAC necrosis & 0 & 0 & $>0.9999$ \\
Overall revision & 5 & 3 & $>0.9999$ \\
\hline
\end{tabular}

IFP groups, respectively. As it could be expected, using a median-split separation for weight of resection ( $\geq 550 \mathrm{vs}$. $<550 \mathrm{~g}$ ) regardless of the operating technique, we found that the drainage volume was significantly $(\mathrm{P}<0.01)$ larger for bigger resections with a trend towards longer drainage time $(\mathrm{P}=0.1426)$.

Among complications, no partial or total NAC necrosis was recorded. In the SMP group, a secondary procedure was necessary in 5 out of 36 patients (14\%). One patient required the drainage of an infected seroma, one patient was treated for residual asymmetry, and 3 cases required scar revision. Hypertrophic scarring was the commonest minor complication (4 cases), while 1 wound dehiscence was treated conservatively. In the IFP group, 3 patients out of $22(14 \%)$ required surgical revision of the scar, a slight
Table 5 Comparison of complications between subgroups of patients (using median-split separation)

\begin{tabular}{lccc}
\hline & $\begin{array}{c}\geq 1 \\
\text { complication }\end{array}$ & $\begin{array}{c}\text { Scar } \\
\text { revision }\end{array}$ & $\begin{array}{c}\text { Overall revision } \\
\text { rate }\end{array}$ \\
\hline Weight of resection & & & \\
$\geq 550 \mathrm{~g}(\mathrm{n}=29)$ & 9 & 3 & 4 \\
$<550 \mathrm{~g}(\mathrm{n}=29)$ & 10 & 3 & 4 \\
P value & 0.7797 & $>0.9999$ & $>0.9999$ \\
SN-Nipple distance & & & \\
$\geq 31 \mathrm{~cm}(\mathrm{n}=30)$ & 11 & 4 & 6 \\
$<31 \mathrm{~cm}(\mathrm{n}=28)$ & 8 & 2 & 2 \\
P value & 0.5116 & 0.6714 & 0.2555 \\
BMl & & & \\
$\geq 28.1(n=29)$ & 9 & 5 & 7 \\
$<28.1(n=29)$ & 10 & 1 & 0.0517 \\
P value & 0.7797 & 0.1936 &
\end{tabular}

asymmetry was noticed in 2 patients while hypertrophic scar and wound dehiscence were treated conservatively in each of the other 2 cases. Globally, complications were balanced across groups, with no significant difference between the SMP group and the IFP group (Table 4). When using a median-split separation for weight of resection $(\geq 550$ $v s .<550 \mathrm{~g}$ ), there was no difference in the complication rate between smaller and larger resections (Table 5). The complication rate following breast reduction in women with a preoperative sternal notch-to-nipple distance $\geq 31 \mathrm{~cm}$ was the same as women with a smaller SN-NIP distance $(<31 \mathrm{~cm})$. When separating groups by median BMI at baseline ( $\geq 28.1 v s .<28.1)$, the complications rate remained similar, even if an overall higher scar revision rate was tendentially $(\mathrm{P}=0.0517)$ more frequent in patients with a larger BMI. There was no statistically significant difference in the revision rate between the SMP group and the IFP group, in patients split by breast resection weight, and in patients split by preoperative SN-NIP distance.

\section{Aesthetic outcomes}

At the end of the follow-up period, surgeons evaluating the aesthetic result gave a significantly higher mean VAS score to patients who underwent a SMP reduction compared to those patients who underwent an IFP reduction $(7.7 \pm 0.7$ 


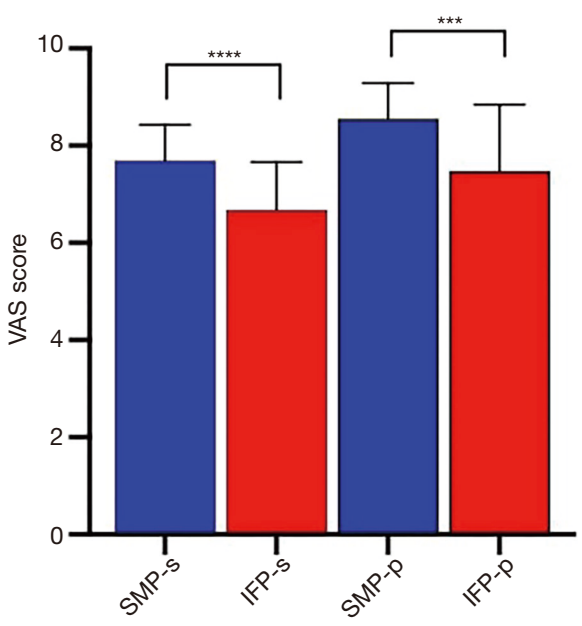

Figure 4 Patients (p) and surgeons' (s) VAS score evaluation of the aesthetic result, depending on the breast reduction technique. A significantly higher mean VAS score was seen in patients who underwent a SMP reduction compared to those patients who underwent an IFP reduction $(7.7 \pm 0.7$ vs. $6.7 \pm 1.0$, respectively. $\left.{ }^{* * *} \mathrm{P}<0.001,{ }^{* * * *} \mathrm{P}<0.0001\right)$. vs. $6.7 \pm 1.0$, respectively, ${ }^{* * * *} \mathrm{P}<0.0001$, all expressed as average \pm SD). Patient's satisfaction matched accordingly, being significantly $\left.{ }^{* * *} \mathrm{P}<0.001\right)$ higher in the SMP group as compared to the IFP group, as the mean aesthetic result VAS score given by patients was $8.6 \pm 0.7$ in the SMP group and $7.5 \pm 1.4$ in the IFP group (all scores are expressed as average value $\pm \mathrm{SD}$ ) (Figures $4-8)$.

\section{Discussion}

Several studies have been performed to evaluate the overtime changes of the breasts after reduction mammoplasties. The inferior pedicle is an established technique and is applicable in a wide range of breast sizes, with low complication rates and good viability of the NAC. However, the "bottoming-out" phenomenon and loss of projection are a major criticism of this technique, namely that of a bothersome problem for patients and surgeons (8). Indeed, the inferior pedicle (IFP) technique attempts to raise the inferior breast tissue superiorly while basing it inferiorly,
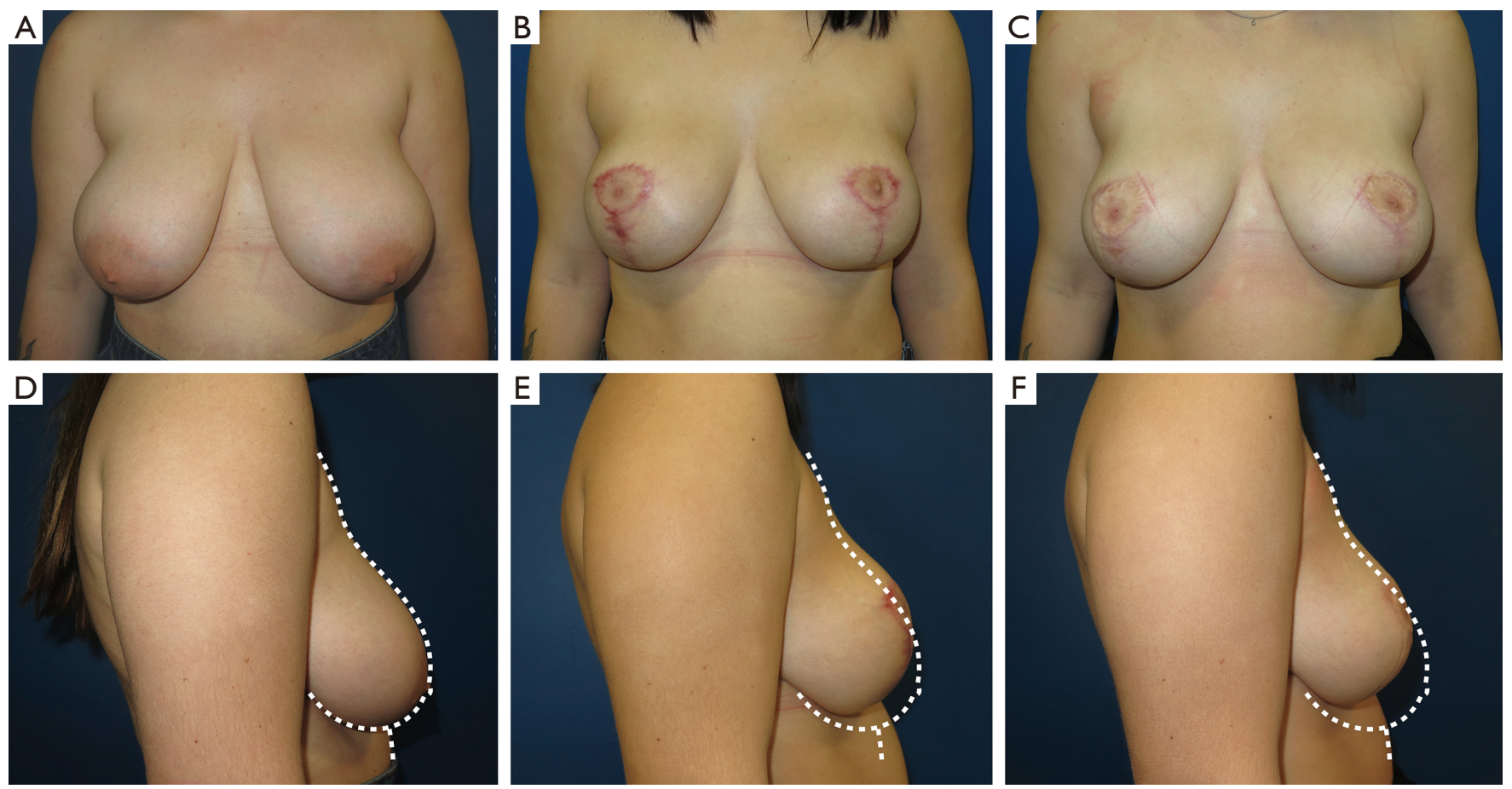

Figure 5 Case nr. 1. (A,D) Preoperative views of a 23-year-old female patient with moderate hypertrophic breasts. (B,E) Postoperative result at 6 months after inferior pedicle-based breast reduction (IFP). (C,F) Result at 24 months after surgery. 

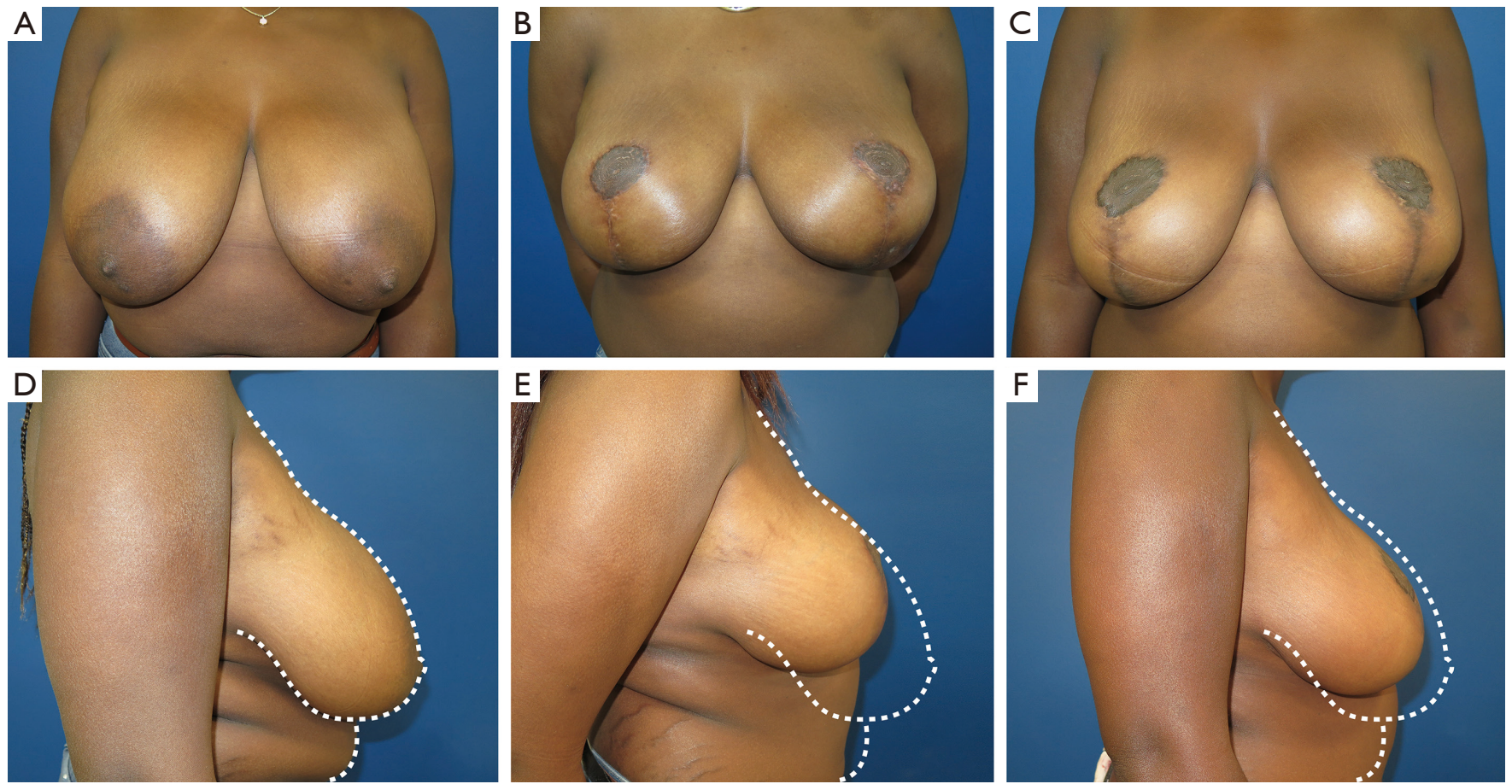

Figure 6 Case nr. 2. (A,D) Preoperative views of a 37-year-old female with severe hypertrophic breasts. (B,E) Postoperative result at 6 months after inferior pedicle-based breast reduction (IFP). (C,F) Result at 24 months after surgery.
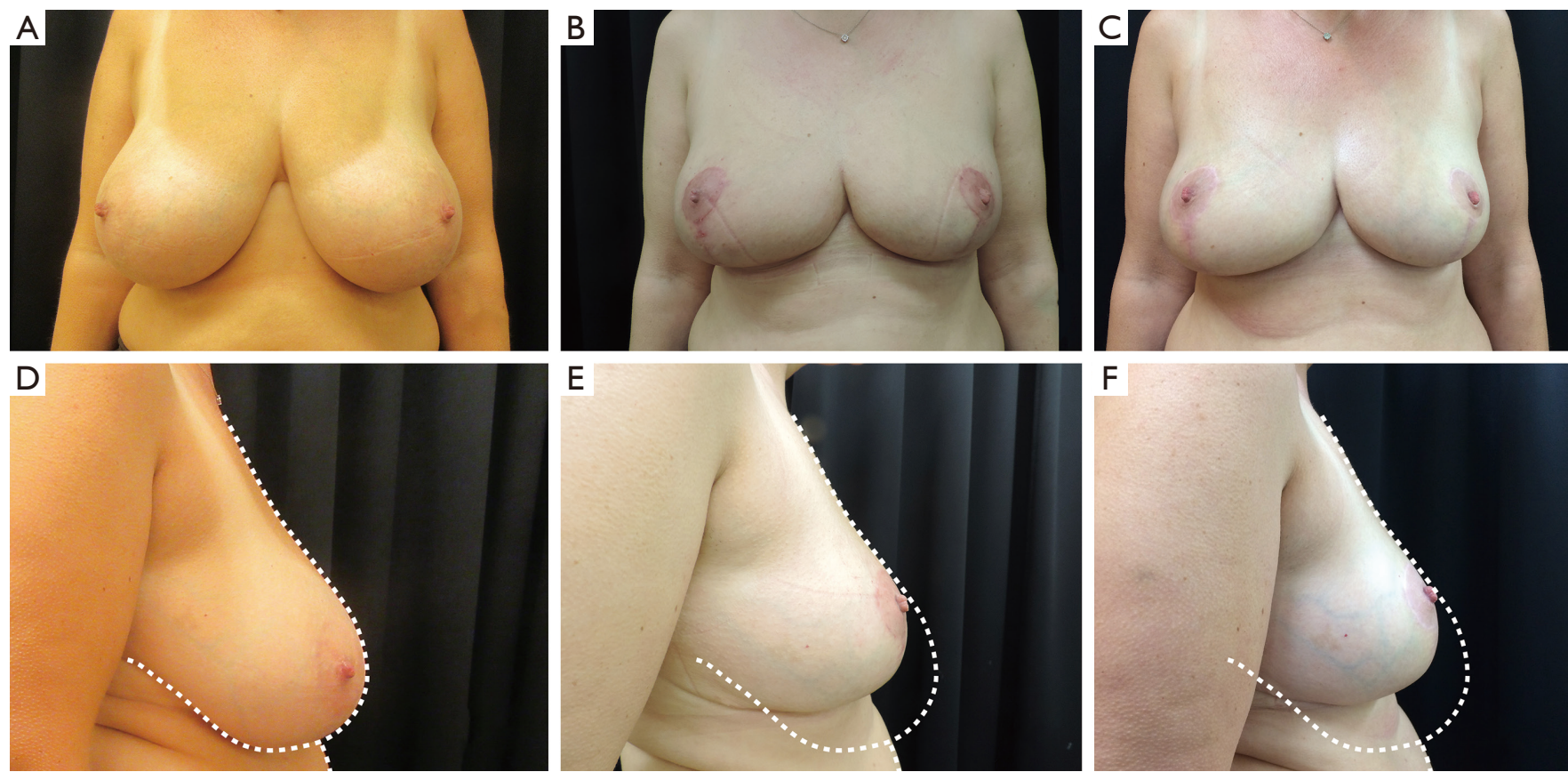

Figure 7 Case nr. 3. (A,D) Preoperative views of a 44-year-old female patient with moderate hypertrophic breasts. (B,E) Postoperative result at 6 months after supero-medial based breast reduction (SMP). (C,F) Result at 24 months after surgery. 

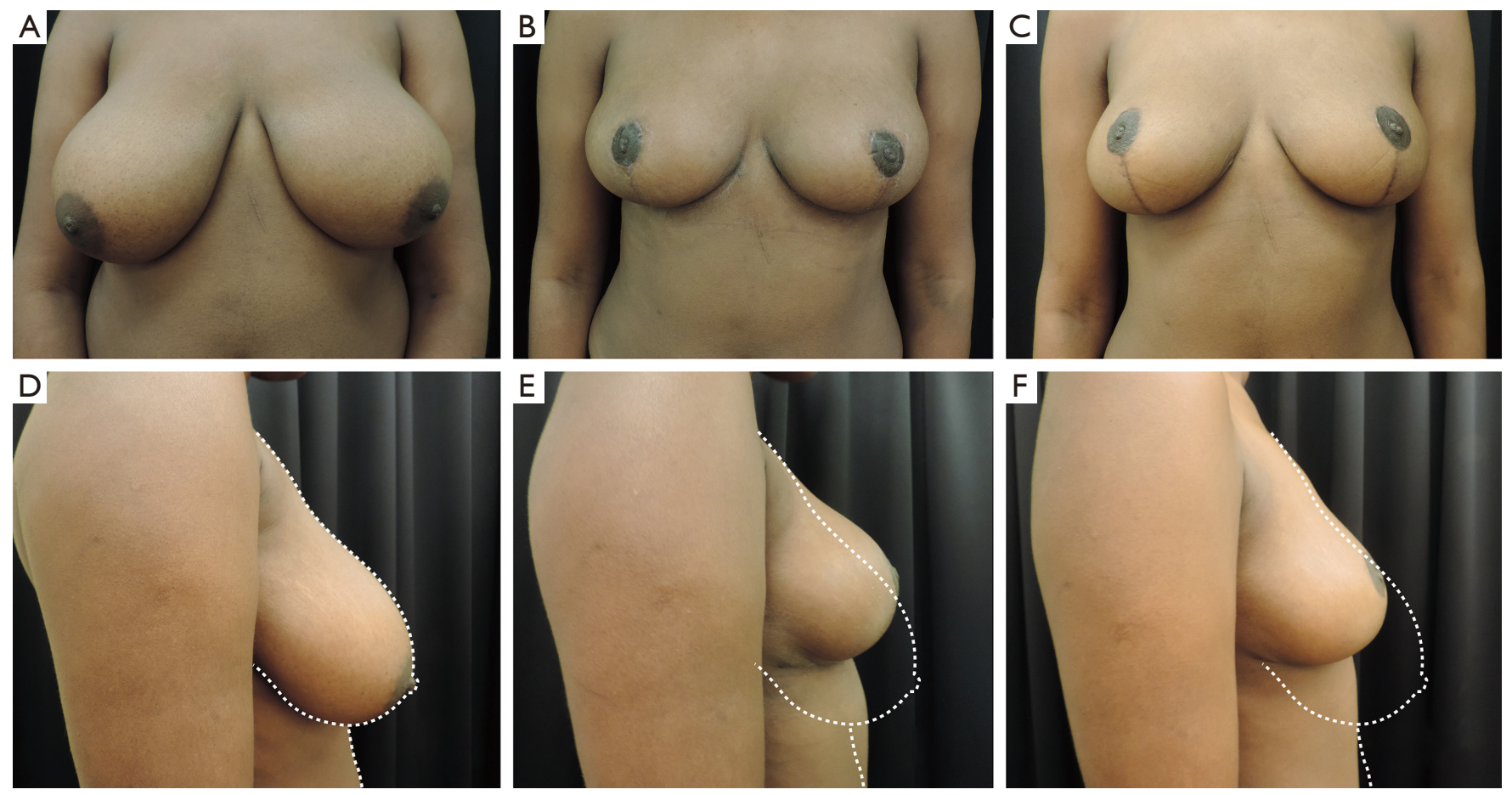

Figure 8 Case nr. 4. (A,D) Preoperative views of a 36-year-old female patient with severe hypertrophic breasts. (B,E) Postoperative result at 6 months after supero-medial based breast reduction (SMP). (C,F) Result at 24 months after surgery.

thus involving two inherently opposing vectors (9). A work analyzing 22 patients with inferior pedicle breast reduction over 5 years, found that the length of the vertical scar and pseudoptosis increased over time (10). However, overall breast projection and shape were maintained, and the sternal-notch to nipple distance did not change, resulting in superior displacement of the NAC in relationship to the breast mound.

Zehm et al. compared the long-term inferior pole length between superior and inferior pedicle breast reduction techniques (11). They found a $3.3-\mathrm{cm}$ mean elongation of the distance from the NAC to the IMF after the superior pedicle Pitanguy technique (with a $454 \mathrm{~g}$ average resection weight), and a $3.9 \mathrm{~cm}$ mean elongation after the IFP technique with a $518 \mathrm{~g}$ average resection. Superomedial pedicle (SMP) reduction mammoplasties have also shown lower pole elongation to a certain extent (12).

Indeed, authors do not always agree on the greater tendency of the inferior pedicle to extend over time, especially in the gigantomachias. In the series of Kemaloglu et al., inferior pedicle mammoplasties were not associated with significantly bigger bottoming out when compared to the superomedial pedicle technique (13). In such gigantomastic patients, bottoming out occurred in both groups with time. Despite this, both pedicle techniques generated acceptable aesthetic outcomes and relieved patient symptoms.

Historically, the SMP has been associated with increased complication rates in large volume reductions, including NAC necrosis rates as high as $10 \%(14,15)$. Since then, the technique has been demonstrated to be both reliable and safe (16). According to a recent literature review (17), complication rates associated with the use of the superomedial pedicle were lower than those associated with the use of the inferior pedicle (16\% vs. 29.7\%). Predisposing factors which increased complication rates when performing superomedial reduction mammoplasty included a $\mathrm{SN}-\mathrm{N}$ distance $>35.5 \mathrm{~cm}$, ptosis grade of 3 , breast reduction weight $>800 \mathrm{~g}$, and BMI >30 $(18,19)$. In our study, no significant differences in terms of complications were recorded between the two groups and the overall complication rate compares favorably with literature $(20,21)$. Regarding the factors predisposing complications, only a BMI $>28.1$ was significantly associated to a higher complications rate, while a tissue resection $>550 \mathrm{~g}$ and the $\mathrm{SN}-\mathrm{N}$ distance were not related. It needs to be acknowledged that based on the low 
number of complications, a statistical analysis on higher "cut-off" values would have been underpowered.

While acknowledging the retrospective pattern of the study, the investigated group were particularly consistent and superimposable in terms of SN-N distance and global breast volume (as confirmed by similar tissue resection and skin redraping) suggesting comparable gland pre-operative weight and skin laxity.

When focusing on breast general shape, Davison et al. (9) described how the superomedial pedicle provides a substantial amount of superomedial fullness by preserving the upper-inner quadrant of the breast, resisting the glandular bottoming-out phenomenon associated with the inferior pedicle, and assuring a better breast shape (15). Our findings are consistent with those described by previous authors, and add some critical information with the long-term comparison with inferior pedicle group. If the difference in SN-N distance increase over time was not dramatic between the groups, a higher ptosis degree and a higher lower pole length elongation would be found in the IFP group, matching a clinically more evident bottoming out. We may assume that such differences may reflect the higher satisfaction rate regarding the aesthetic outcomes achieved at last follow-up for patients included in the SMP group.

Moreover, the SMP technique procedures proved to be tendentially faster. Those results were attributed to decreased flap de-epithelialization, minimal superior flap creation or undermining, and single en bloc resection of breast parenchyma (5). In our series this was not statistically significant despite the presence of a strong trend. This may be due to the fact that procedures were performed by the consultant surgeon assisted by a resident in training, making the differences in operative time potentially dependent not only on the technique used, but also on the learning curve of each trainee.

Some study limitations need to be acknowledged. Firstly, the study is retrospective and the patients were not randomized, with potential risks of selection bias. Moreover, considering the relatively small sample size, no definitive conclusion can be drawn in terms of safety and aesthetic results. On the other hand, the two group were homogeneous in terms of pre-operative characteristics, all patients were treated by the same leading surgeon and were followed for a relatively long follow-up period.

\section{Conclusions}

In our 2-year follow-up study we compared the inferior pedicle and the superomedial pedicle breast reduction on a relevant and homogeneous cohort of patients, focusing particularly on the long-term breast shape. According to our findings, we believe that the SMP technique provides stable and satisfactory results in terms of breast shape, improving some of the major concerns related to the use of an IFP technique (i.e., lower pole elongation and ptosis recurrence) and maintaining a superimposable rate of adverse events.

\section{Acknowledgments}

Funding: None.

\section{Footnote}

Reporting Checklist: The authors have completed the STROBE reporting checklist. Available at http://dx.doi. org/10.21037/gs-20-440

Data Sharing Statement: Available at http://dx.doi. org/10.21037/gs-20-440

Peer Review File: Available at http://dx.doi.org/10.21037/gs20-440

Conflicts of Interest: All authors have completed the ICMJE uniform disclosure form (available at http://dx.doi. org/10.21037/gs-20-440). The authors have no conflicts of interest to declare.

Ethical Statement: The authors are accountable for all aspects of the work in ensuring that questions related to the accuracy or integrity of any part of the work are appropriately investigated and resolved. The study was conducted in accordance with the Declaration of Helsinki (as revised in 2013). Individual consent for this retrospective analysis, including approval for photographic \video documentation, was gathered from all patients. The 'Commission cantonale d'éthique de la recherche sur l'être humain CER-VD’ approved the study, project ID 02512.

Open Access Statement: This is an Open Access article distributed in accordance with the Creative Commons Attribution-NonCommercial-NoDerivs 4.0 International License (CC BY-NC-ND 4.0), which permits the noncommercial replication and distribution of the article with the strict proviso that no changes or edits are made and the original work is properly cited (including links to both the 
formal publication through the relevant DOI and the license). See: https://creativecommons.org/licenses/by-nc-nd/4.0/.

\section{References}

1. 2016 Plastic Surgery Statistics Report. 2016. Available online: https://www.plasticsurgery.org/news/plasticsurgery-statistics. Accessed July 13, 2017.

2. Rogliani M, Gentile P, Labardi L, et al. Improvement of physical and psychological symptoms after breast reduction. J Plast Reconstr Aesthet Surg 2009;62:1647-9.

3. Okoro SA, Barone C, Bohnenblust M, et al. Breast reduction trend among plastic surgeons: a national survey. Plast Reconstr Surg 2008;122:1312-20.

4. Rohrich RJ, Gosman AA, Brown SA, et al. Current preferences for breast reduction techniques: a survey of board-certified plastic surgeons 2002. Plast Reconstr Surg 2004;114:1724-33; discussion 1734-6.

5. Brownlee P, Chesire D, Crandall M, et al. Superomedial pedicle reduction mammaplasty: increased resection weight does not increase nipple necrosis. J Surg Res 2017;219:158-64.

6. Regnault P. Breast ptosis. Definition and treatment. Clin Plast Surg 1976;3:193-203.

7. Zavrides H. The Classic Pitanguy Technique and Its Modifications in Mammaplasty: Ten Years of Experiences. Ann Plast Surg 2017;79:433-7.

8. Meshulam-Derazon S, Barnea Y, Zaretski A, et al. Largevolume breast reduction: Long-term results. Scand J Plast Reconstr Surg Hand Surg 2009;43:65-70.

9. Davison SP, Mesbahi AN, Ducic I, et al. The versatility of the superomedial pedicle with various skin reduction patterns. Plast Reconstr Surg 2007;120:1466-76.

10. Reus WF, Mathes SJ. Preservation of projection after reduction mammaplasty: long-term follow-up of the inferior pedicle technique. Plast Reconstr Surg 1988;82:644-52.

11. Zehm S, Puelzl P, Wechselberger G, et al. Inferior pole length and long-term aesthetic outcome after superior and

Cite this article as: Sapino G, Haselbach D, Watfa W, Baudoin J, Martineau J, Guillier D, di Summa PG. Evaluation of long-term breast shape in inferior versus superomedial pedicle reduction mammoplasty: a comparative study. Gland Surg 2021;10(3):1018-1028. doi: 10.21037/gs-20-440 inferior pedicled reduction mammaplasty. Aesthetic Plast Surg 2012;36:1128-33.

12. Altuntas ZK, Kamburoglu HO, Yavuz N, et al. Longterm changes in nipple-areolar complex position and inferior pole length in superomedial pedicle inverted ' $t$ ' scar reduction mammaplasty. Aesthetic Plast Surg 2015;39:325-30.

13. Kemaloglu CA, Ozocak H. Comparative Outcomes of Inferior Pedicle and Superomedial Pedicle Technique With Wise Pattern Reduction in Gigantomastic Patients. Ann Plast Surg 2018;80:217-22.

14. Landau AG, Hudson DA. Choosing the superomedial pedicle for reduction mammaplasty in gigantomastia. Plast Reconstr Surg 2008;121:735-9.

15. Lugo LM, Prada M, Kohanzadeh S, et al. Surgical outcomes of gigantomastia breast reduction superomedial pedicle technique: a 12-year retrospective study. Ann Plast Surg 2013;70:533-7.

16. Hall-Findlay EJ. Vertical breast reduction with a mediallybased pedicle. Aesthet Surg J 2002;22:185-94.

17. Bauermeister AJ, Gill K, Zuriarrain A, et al. "Reduction mammaplasty with superomedial pedicle technique: A literature review and retrospective analysis of 938 consecutive breast reductions". J Plast Reconstr Aesthet Surg 2019;72:410-8.

18. Brown RH, Siy R, Khan K, et al. The Superomedial Pedicle Wise-Pattern Breast Reduction: Reproducible, Reliable, and Resilient. Semin Plast Surg 2015;29:94-101.

19. Fischer JP, Cleveland EC, Shang EK, et al. Complications following reduction mammaplasty: a review of 3538 cases from the 2005-2010 NSQIP data sets. Aesthet Surg J 2014;34:66-73.

20. Wagner DS, Alfonso DR. The influence of obesity and volume of resection on success in reduction mammaplasty: an outcomes study. Plast Reconstr Surg 2005;115:1034-8.

21. Brown AP, Hill C, Khan K. Outcome of reduction mammaplasty--a patients' perspective. Br J Plast Surg 2000;53:584-7. 